\title{
Impact of Continuity of Care on Mortality and Health Care Costs: A Nationwide Cohort Study in Korea
}

\author{
Dong Wook Shin, MD, DrPH, MBA \\ Jubee Cho, MA, PbD \\ Hyung Kook Yang, MD, MPH \\ Jae Hyun Park, MD, MPH, PbD \\ Hyejin Lee, MD, MPH \\ Hyunsu Kim, MD \\ Jubwan Ob, MD, MPH, DrPH \\ Soobee Hwang, MS, PbD \\ BeLong Cho, MD, MPH, PbD \\ Eliseo Guallar, MD, MPH, DrPH
}

\begin{abstract}
PURPOSE Continuity of care is considered a core element of high-quality primary care, but its impact on mortality and health care costs is unclear. We aimed to determine the impact of continuity of care on mortality, costs, and health outcomes in patients with newly diagnosed cardiovascular risk factors.
\end{abstract}

METHODS We conducted a cohort study of a 3\% nationwide random sample of Korean National Health Insurance enrollees. A total of 47,433 patients who had received new diagnoses of hypertension, diabetes, hypercholesterolemia, or their complications in 2003 or 2004 were included. We determined standard indices of continuity of care-most frequent provider continuity (MFPC), modified, modified continuity index (MMCI), and continuity of care index (COC)-and evaluated their association with study outcomes over 5 years of follow-up. Outcome measures included overall mortality, cardiovascular mortality, incident cardiovascular events, and health care costs.

RESULTS The multivariable-adjusted hazard ratios (HRs) for all-cause mortality, cardiovascular mortality, incident myocardial infarction, and incident ischemic stroke comparing participants with $\mathrm{COC}$ index below the median to those above the median were $\mathrm{HR}=1.12(95 \% \mathrm{Cl}, 1.04-1.21), 1.30$ (1.13-1.50), 1.57 (1.281.95), and 1.44 (1.27-1.63), respectively. Similar findings were obtained for other indices of continuity of care. Lower continuity of care was also associated with increased inpatient and outpatient days and costs.

CONCLUSIONS Lower indices of continuity of care in patients with newly diagnosed hypertension, diabetes, and hypercholesterolemia were associated with higher all-cause and cardiovascular mortality, cardiovascular events, and health care costs. Health care systems should be designed to support long-term trusting relationships between patients and physicians.

Ann Fam Med 2014;12:534-541. doi: 10.1370/afm.1685

\section{INTRODUCTION}

\section{Conflicts of interest: authors report none.}

\author{
CORRESPONDING AUTHOR \\ BeLong Cho, MD, MPH, PhD \\ Department of Family Medicine \\ Seoul National University Hospital \\ 101 Daehak-ro, Jongno-gu \\ Seoul, South Korea, 110-744 \\ belong@snu.ac.kr \\ or \\ Eliseo Guallar, MD, MPH, DrPH \\ Department of Epidemiology \\ Johns Hopkins Bloomberg School of Public \\ Health \\ 2024 E. Monument St., Room 2-639 \\ Baltimore, MD 21205 \\ eguallar@jhsph.edu
}

ontinuity of care, defined as a sustained partnership between patient
and clinician, is considered a core element of high-quality primary
care. ${ }^{1,2}$ Theoretically, a "personal doctor" with accumulating knowl-
edge of the patient's history and values could provide better care at lower
cost. ${ }^{3}$ However, changes in health care management, including shifts toward
multidisciplinary group practices and forced discontinuities due to insurance
change, are undermining continuity of care in the United States ${ }^{4-6}$ and else-
where ${ }^{7-9}$ As a consequence, there is substantial interest in understanding the
role of continuity of care in determining health care outcomes and costs.
Continuity of care has been associated with better quality of care ${ }^{11,12}$
and with improved patient adherence and self-management, ${ }_{1}^{11,13-15}$ improved
outcomes, ${ }^{15,16}$ and lower health care utilization and costs, ${ }^{17-22}$ but the evi-
dence is inconsistent. ${ }^{23-26}$ Furthermore, previous studies have often been
affected by methodological limitations, ${ }^{2}$ including unrepresentative sam-
ples, ${ }^{12,15,17,18,21}$ use of non-validated measures for continuity of care and out-
comes ${ }_{,}^{11,14,17,18}$ temporal ambiguity in the relationship between continuity of
care and outcomes, ${ }^{12,17,18,20,21}$ and short follow-up. ${ }^{15,21,22,27,28}$ Only one cohort 
study has found that continuity of care with a primary care physician was associated with lower mortality. ${ }^{29}$ However, the study was restricted to older adults, and it did not investigate potential mechanisms of the association. Recent studies from the United Kingdom also suggest the association between continuity of care and reduced mortality, but they were limited by inconsistent results and the cross-sectional nature of one study. ${ }^{30,31}$

We aimed to determine the impact of continuity of care on survival and health care costs in patients with newly diagnosed cardiovascular risk factors, since these represent important, preventable chronic conditions ${ }^{32,33}$ to which continuity of care is likely to be highly relevant. ${ }^{11,15,34-37}$ In South Korea, virtually all Koreans (97\%) are covered by National Health Insurance (KNHI), and may consult any primary care physician. (In Korea, primary care physicians work mostly in solo private practices and are reimbursed on a fee-for-service basis.) This system enables patients to choose and retain an individual physician regardless of changes in employment status. To that extent it promotes an ongoing interpersonal relationship between patient and physician and provides an excellent opportunity to evaluate the consequences of continuity of care. ${ }^{38}$

\section{METHODS}

\section{Study Population}

We studied a $3 \%$ random sample $(n=1,162,234)$ of $\mathrm{KNHI}$ enrollees who were aged at least 20 years on December 31, 2002. Eliminating those who had submitted claims for cancer or cardiovascular disease in 2002 left 970,192 who were free of such disease at the end of 2002. From that pool, we then selected 48,347 subjects with new claims for the diagnosis of hypertension, diabetes, hypercholesterolemia, or their complications during 2003 or 2004 and at least 4 claims during the first 2 years after the initial visit. We chose those criteria for visit frequency ${ }^{15,19,27,35,39}$ and time frame $\mathrm{e}^{18,29}$ on the basis of our literature review, considering that (1) it would be difficult to construct stable measures of continuity for patients with fewer visits ${ }^{15,27}$; (2) semiannual visits are the desirable minimum for the management of the target conditions; and (3) a 2-year window may ensure longitudinal continuity. ${ }^{29}$ After excluding 974 subjects who died during the first 2 years after their first visit, a total of 47,433 subjects were included in our study (Figure 1).

In Korea, biennial health check-ups are provided to KNHI enrollees aged 40 years and older and to all employees or employers regardless of age. ${ }^{40}$ The program is targeted to the identification of chronic disease risk factors, and patients receive educational counseling or referral for treatment as indicated. To determine the role of continuity of care independent of conventional lifestyle factors, which cannot be adjusted in claims data, we identified the subset of study participants who underwent screening in the health check-up program in 2003 to $2004(\mathrm{n}=18,206$; $38.4 \%)$ and obtained their lifestyle data, including smoking, drinking, and body mass index.

This study was approved by the Institutional Review Board of the Seoul National University. The requirement for informed consent was waived because the study was based on routinely collected administrative or claims data.

\section{Data Sources and Measures}

$\mathrm{KNHI}$ collects all necessary information for reimbursement of each medical service, including basic patient information, identifier for clinic or hospital, disease code, and costs incurred. Patient information includes age, sex, average monthly insurance premium (a proxy for household income), and residential area (categorized as city area, metropolitan area, and rural area).

Continuity of care was measured with $3 \mathrm{com}$ monly used indices ${ }^{19,41}$ : most frequent provider continuity (MFPC) ${ }_{1}^{42}$ modified, modified continuity index $(\mathrm{MMCI}),{ }^{27,43}$ and continuity-of-care index (COC) ${ }^{44}$ (Sup-

\section{Figure 1. Flowchart of study participants.}

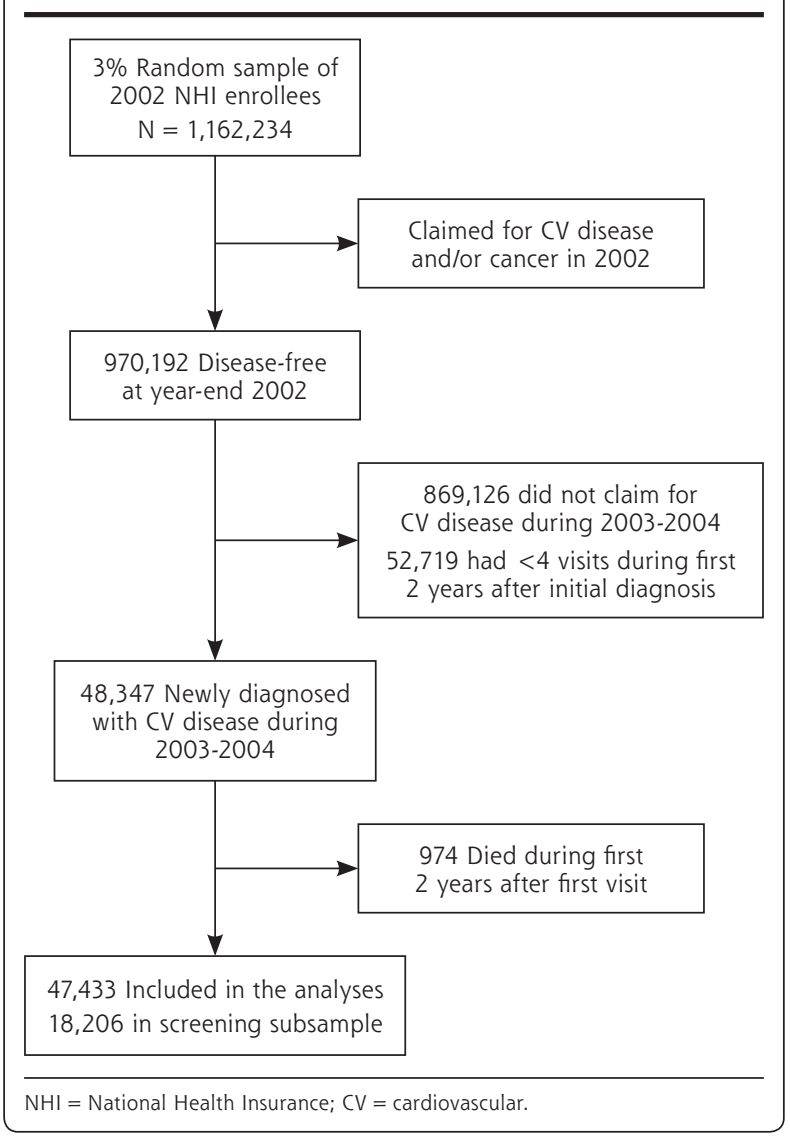


plemental Appendix 1). MFPC primarily measures the concentration of visits with the clinician most often seen, while MMCI focuses on the dispersion across clinicians, ${ }^{27}$ and $\mathrm{COC}$ integrates both aspects into a single metric.

The primary outcome of the study was all-cause mortality. Secondary outcomes were cardiovascular mortality, as identified from death certificate data in the national death registry, and incidence of myocardial infarction, ischemic stroke, and hemorrhagic stroke, as identified only from inpatient hospital claim records to minimize bias from overcoding.

Health care utilization and health care cost incurred were calculated using KNHI claims data and included number of inpatient and outpatient days and expenses claimed with diagnosis codes of hypertension, diabetes, hypercholesterolemia, or related conditions during the period from 2005 to 2010. Pharmaceutical costs were not included.

\section{Statistical Analysis}

The primary analysis was based on Cox proportional hazards models in which continuity of care was measured in the first 2 years after diagnosis and outcomes accrued in subsequent years. Survival time was thus calculated as the time between 2 years after diagnosis and the date of death (or date of first hospitalization for cardiovascular outcomes), or December 31, 2010, whichever was first. Considering the highly skewed distribution of the indices, each index of continuity of care was dichotomized at its median. A sensitivity analysis was performed excluding the last 1 year before death to see if continuity of care antecedent to this point is significantly related to subsequent mortality.

For secondary analysis, we used a time-dependent Cox proportional hazards model in which each continuity-of-care index was calculated for each 2-year interval from the date of diagnosis ${ }^{29}$ and dichotomized within each time frame. If the visit frequency was less than 4 during a 2-year time frame, continuity of care was considered to be low, since such low visit frequency would not be sufficient for appropriate management of chronic conditions. Additional sensitivity analysis was performed, separating the continuity of care levels into above median, below median, and less than 4 visits.

Multivariate analyses were performed by adjusting for age, ${ }^{18,27}$ sex, ${ }^{18,27}$ income, Charlson comorbidity index based on claims data in the year before diagnosis, $18,27,29$ number of visits during the first 2 years, ${ }_{1}^{18,27}$ and residential area. ${ }^{27}$ To examine whether the association of continuity-of-care measures with outcomes could be confounded by other health behaviors, we performed sensitivity analyses in the screening subset, which allowed further adjustment for smoking status (current, past, never), ${ }^{29}$ drinking status (current drinker vs oth- ers), ${ }_{1}^{29}$ and body mass index (categorized as $<18.5,18.5$ 23, 23-25, or $>25$ according to Asian obesity criteria). ${ }^{29}$ Further sensitivity analyses were performed in the secondary analysis, with Charlson comorbidity index, number of visits, and visits to tertiary-care hospitals in the previous years as additional time-dependent covariates.

Inpatient and outpatient days and costs were calculated by summing all days and costs during 2005-2010. Results for the high- and low-continuity groups were compared using multivariable linear regression models. All analyses were performed with SAS 9.2 (SAS Institute) and Stata 12.0 (Stata Corp). Two-sided $P$ values $<0.05$ were considered statistically significant.

\section{RESULTS}

The mean age of study participants was $54.2(\mathrm{SD}=12.5)$ years, with similar proportions of females and males. The average number of visits during the first 2 years was $14.4(\mathrm{SD}=7.9)($ Table 1$)$. The median values of

\section{Table 1. Description of Study Population $(\mathrm{N}=47,433)$}

\begin{tabular}{lc}
\hline Characteristics & Value \\
\hline Age, years & \\
Mean (SD) & $54.2(12.5)$ \\
Median (range) & $54(20-100)$ \\
Sex, No. (\%) & \\
Male & $24,060(50.7)$ \\
Female & $23,373(49.3)$ \\
Premium in Korean won ${ }^{\text {a }}$ & \\
Mean (SD) & $45,567(37,077)$ \\
Income level, No. (\%) & \\
1st quartile; low & $12,062(25.4)$ \\
2nd quartile & $11,692(24.6)$ \\
3rd quartile & $12,360(26.1)$ \\
4th quartile; high & $11,319(23.9)$ \\
Place of residence, No. (\%) & \\
Metropolitan area & $24,742(52.8)$ \\
City area & $16,830(35.9)$ \\
Rural area & $5,327(11.4)$ \\
Charlson comorbidity score & \\
$\quad$ Mean (SD) & $0.49(0.81)$ \\
Median (range) & $0(0-11)$ \\
Number of visits, mean (SD) & \\
During the first 2 years & $14.4(7.9)$ \\
During the second 2 years & $14.2(10.9)$ \\
During the third 2 years & $15.7(14.7)$ \\
Continuity of care indices, median & \\
Mosterquartile range) & $0.88(0.67-1.00)$ \\
Modified, modified continuity index & \\
(MMCI) & \\
Continuity of care index (COC) & \\
\hline 11 (US) = W1,100 (Korean won), as of 2012. & \\
\hline
\end{tabular}


Table 2. Risk of Death and Cardiovascular Endpoints by Level of Continuity of Care $(N=47,433)$

\begin{tabular}{|c|c|c|c|c|c|c|}
\hline \multirow[b]{2}{*}{ Endpoint } & \multicolumn{2}{|c|}{$\begin{array}{l}\text { Most Frequent } \\
\text { Provider Continuity }\end{array}$} & \multicolumn{2}{|c|}{$\begin{array}{l}\text { Modified, Modified } \\
\text { Continuity Index }\end{array}$} & \multicolumn{2}{|c|}{$\begin{array}{l}\text { Continuity of Care } \\
\text { Index }\end{array}$} \\
\hline & $\begin{array}{c}\text { Above } \\
\text { Median }\end{array}$ & $\begin{array}{c}\text { Below } \\
\text { Median }\end{array}$ & $\begin{array}{c}\text { Above } \\
\text { Median }\end{array}$ & $\begin{array}{c}\text { Below } \\
\text { Median }\end{array}$ & $\begin{array}{c}\text { Above } \\
\text { Median }\end{array}$ & $\begin{array}{c}\text { Below } \\
\text { Median }\end{array}$ \\
\hline \multicolumn{7}{|l|}{ All cause mortality } \\
\hline No. of deaths (deaths per 1,000 py) & $1,340(11.5)$ & $1,787(15.4)$ & $1,296(11.3)$ & $1,831(15.5)$ & $1,345(11.6)$ & $1,782(15.4)$ \\
\hline Crude HR $(95 \% \mathrm{Cl})$ & 1.00 (Ref) & $1.33(1.24-1.43)$ & 1.00 (Ref) & $1.37(1.28-1.47)$ & 1.00 (Ref) & $1.33(1.24-1.43)$ \\
\hline Multivariable-adjusted HR $(95 \% \mathrm{Cl})$ & 1.00 (Ref) & $1.13(1.05-1.21)$ & 1.00 (Ref) & $1.13(1.05-1.21)$ & 1.00 (Ref) & $1.12(1.04-1.21)$ \\
\hline \multicolumn{7}{|l|}{ Cardiovascular mortality } \\
\hline No. of deaths (deaths per 1,000 py) & $321(2.8)$ & $494(4.3)$ & $299(2.6)$ & $516(4.4)$ & $321(2.8)$ & $494(4.3)$ \\
\hline Crude HR $(95 \% \mathrm{Cl})$ & 1.00 (Ref) & $1.54(1.34-1.77)$ & 1.00 (Ref) & $1.67(1.45-1.93)$ & 1.00 (Ref) & $1.54(1.34-1.77)$ \\
\hline Multivariable-adjusted HR $(95 \% \mathrm{Cl})$ & 1.00 (Ref) & $1.30(1.12-1.50)$ & 1.00 (Ref) & $1.40(1.21-1.62)$ & 1.00 (Ref) & $1.30(1.13-1.50)$ \\
\hline \multicolumn{7}{|l|}{ Noncardiovascular mortality } \\
\hline No. of deaths (deaths per 1,000 py) & $1,019(8.8)$ & $1,293(11.1)$ & $997(8.7)$ & $1,315(11.2)$ & $1,024(8.8)$ & $1,288(11.1)$ \\
\hline Crude HR $(95 \% \mathrm{Cl})$ & 1.00 (Ref) & $1.27(1.17-1.38)$ & 1.00 (Ref) & $1.28(1.18-1.39)$ & 1.00 (Ref) & $1.26(1.16-1.37)$ \\
\hline Multivariable-adjusted HRa $(95 \% \mathrm{Cl})$ & 1.00 (Ref) & $1.07(0.99-1.17)$ & 1.00 (Ref) & $1.05(0.96-1.14)$ & 1.00 (Ref) & $1.07(0.98-1.16)$ \\
\hline \multicolumn{7}{|l|}{ Myocardial infarction ${ }^{\mathrm{a}}$} \\
\hline $\begin{array}{l}\text { No. of incident events (incident } \\
\text { events per } 1,000 \text { py) }\end{array}$ & $144(1.2)$ & $232(2.0)$ & $147(1.3)$ & $229(1.9)$ & $144(1.2)$ & $232(2.0)$ \\
\hline Crude HR $(95 \% \mathrm{Cl})$ & 1.00 (Ref) & $1.61(1.31-1.98)$ & 1.00 (Ref) & $1.51(1.23-1.86)$ & 1.00 (Ref) & $1.62(1.31-1.99)$ \\
\hline Multivariable-adjusted HR $(95 \% \mathrm{Cl})$ & 1.00 (Ref) & $1.57(1.27-1.94)$ & 1.00 (Ref) & $1.51(1.22-1.87)$ & 1.00 (Ref) & $1.57(1.28-1.95)$ \\
\hline \multicolumn{7}{|l|}{ Cerebral infarction ${ }^{b}$} \\
\hline $\begin{array}{l}\text { No. of incident events (incident } \\
\text { events per } 1,000 \text { py) }\end{array}$ & $427(3.8)$ & $668(6.0)$ & $422(3.8)$ & $673(6.0)$ & $427(3.8)$ & $668(6.0)$ \\
\hline Crude HR $(95 \% \mathrm{Cl})$ & 1.00 (Ref) & $1.59(1.41-1.80)$ & 1.00 (Ref) & $1.58(1.40-1.78)$ & 1.00 (Ref) & $1.60(1.41-1.80)$ \\
\hline Multivariable-adjusted HRa $(95 \% \mathrm{Cl})$ & 1.00 (Ref) & $1.43(1.27-1.62)$ & 1.00 (Ref) & $1.43(1.26-1.63)$ & 1.00 (Ref) & $1.44(1.27-1.63)$ \\
\hline \multicolumn{7}{|l|}{ Cerebral hemorrhage $^{b}$} \\
\hline $\begin{array}{l}\text { No. of incident events (incident } \\
\text { events per } 1,000 \text { py) }\end{array}$ & $141(1.2)$ & $184(1.6)$ & $136(1.2)$ & $189(1.6)$ & $141(1.2)$ & $184(1.6)$ \\
\hline Crude HR $(95 \% \mathrm{Cl})$ & 1.00 (Ref) & $1.30(1.05-1.62)$ & 1.00 (Ref) & $1.35(1.08-1.68)$ & 1.00 (Ref) & $1.31(1.05-1.63)$ \\
\hline Multivariable-adjusted HRa $(95 \% \mathrm{Cl})$ & 1.00 (Ref) & $1.19(0.95-1.49)$ & 1.00 (Ref) & $1.20(0.96-1.52)$ & 1.00 (Ref) & $1.19(0.95-1.49)$ \\
\hline
\end{tabular}

MFPC, MMCI, and COC were 0.88 (interquartile range, $0.67-1.00), 0.93$ (0.84-1.00), and 0.77 (0.49-1.00), respectively. During 5 years of follow-up, we observed 3,127 deaths (13.5 per 1,000 person-years). The numbers of incident cases of myocardial infarction, ischemic stroke, and hemorrhagic stroke were 376, 1,095, and 325 , respectively $(1.6,4.9$, and 1.4 per 1,000 personyears, respectively). The screening subset showed similar demographic and health care use characteristics (Supplemental Appendix 2).

Patients with continuity-of-care measures below the median were at increased risk of mortality compared with those with continuity of care above the median (Table 2). The multivariable-adjusted hazard ratios (HR) for all-cause mortality comparing patients below to patients above median MFPC, MMCI, and COC values were as follows: $\mathrm{HR}=1.13(95 \% \mathrm{CI}, 1.05-1.21)$, 1.13 (1.05-1.21), and 1.12 (1.04-1.21), respectively. The impact of continuity of care on mortality was largely restricted to cardiovascular mortality. The hazard ratios for cardiovascular mortality comparing patients below to patients above median MFPC, MMCI, and COC values were 1.30 (1.12-1.50), 1.40 (1.21-1.62), and 1.30 (1.13-1.50), respectively, while the corresponding estimates for non-cardiovascular mortality were 1.07 (0.99$1.17), 1.05(0.96-1.14)$, and $1.07(0.98-1.16)$, respectively. Neither using continuity-of-care indices as continuous variables nor excluding the last 1 year before death from the analysis changed the results (results not shown).

The association of measures of continuity of care with the risk of incident myocardial infarction and ischemic stroke were markedly stronger (Table 2). For instance, the hazard ratios comparing patients above to those below median levels of COC were 1.57 (95\% CI, 1.28-1.95) and 1.44 (1.27-1.63) for myocardial infarction and ischemic stroke, respectively. The associations for hemorrhagic stroke were weaker and not statistically significant. 
The findings were consistent when the analysis was based on updated measures of continuity of care in time-dependent analyses (Table 3), and when the analyses were restricted to patients in the screening subset even after further adjustment of smoking, alcohol consumption, and body mass index (Supplemental Appendixes 3 and 4). Neither 3-level classification of the continuity of care nor inclusion of Charlson comorbidity index, number of visits, and visits to tertiary-care hospitals in the previous years as additional time-dependent covariates changed the results (Supplemental Appendixes 5 to 7).

Continuity-of-care measures were also associated with inpatient and outpatient days and costs. Patients with above-median COC had significantly fewer $(P$ $<0.001)$ inpatient and outpatient days and lower inpatient and outpatient costs compared with patients with below-median COC (Table 4). The differences for MFPC and MMCI were very similar. The findings in the subsample of patients with additional adjustment were also consistent (Supplemental Appendix 8).

\section{DISCUSSION}

In this large cohort study of patients with newly diagnosed hypertension, diabetes, or hypercholes- terolemia, higher continuity of care was associated with lower overall and cardiovascular mortality, lower incidence of cardiovascular events, and reduced health care utilization and costs, even after controlling for potential confounders including comorbidities and total number of clinician visits. Our study is the first to show a survival benefit of increased continuity of care in a representative sample of newly diagnosed patients. The use of newly diagnosed patients, the large sample size, the high follow-up rate, and the robustness of our findings irrespective of choice of continuity measure, analytical methods, and covariate adjustment, add to the strength of our study. While our findings cannot be generalized to other conditions, our results suggest that continuity of care is a robust predictor of outcomes in patients for conditions with available effective preventive interventions.

\section{Findings and Possible Explanations}

We found an inverse association between continuity of care and future clinical cardiovascular outcomes. A physician who attends the same patient regularly is likely to have better knowledge of him or her, to recognize problems earlier, ${ }^{45}$ and to provide higher quality of care. ${ }^{11,12}$ Furthermore, patients who have continuity with the same physician are more likely to adopt

Table 3. Risk of Death and Cardiovascular Outcomes by Level of Continuity of Care in Time-Dependent Analyses $(\mathrm{N}=47,433)$

\begin{tabular}{|c|c|c|c|c|c|c|}
\hline \multirow[b]{2}{*}{ Outcome } & \multicolumn{2}{|c|}{$\begin{array}{l}\text { Most Frequent } \\
\text { Provider Continuity }\end{array}$} & \multicolumn{2}{|c|}{$\begin{array}{l}\text { Modified, Modified } \\
\text { Continuity Index }\end{array}$} & \multicolumn{2}{|c|}{$\begin{array}{l}\text { Continuity of Care } \\
\text { Index }\end{array}$} \\
\hline & $\begin{array}{l}\text { Above } \\
\text { Median }\end{array}$ & $\begin{array}{l}\text { Below } \\
\text { Median }\end{array}$ & $\begin{array}{l}\text { Above } \\
\text { Median }\end{array}$ & $\begin{array}{l}\text { Below } \\
\text { Median }\end{array}$ & $\begin{array}{l}\text { Above } \\
\text { Median }\end{array}$ & $\begin{array}{l}\text { Below } \\
\text { Median }\end{array}$ \\
\hline \multicolumn{7}{|l|}{ All cause death } \\
\hline Crude HR $(95 \% \mathrm{CI})$ & 1.00 (Ref) & $1.48(1.38-1.59)$ & 1.00 (Ref) & $1.49(1.39-1.61)$ & 1.00 (Ref) & $1.48(1.38-1.59)$ \\
\hline Multivariable-adjusted HRa $(95 \% \mathrm{Cl})$ & 1.00 (Ref) & $1.32(1.23-1.42)$ & 1.00 (Ref) & $1.30(1.21-1.41)$ & 1.00 (Ref) & $1.32(1.23-1.42)$ \\
\hline \multicolumn{7}{|l|}{ Cardiovascular mortality } \\
\hline Crude HR $(95 \% \mathrm{CI})$ & 1.00 (Ref) & $1.54(1.34-1.78)$ & 1.00 (Ref) & $1.68(1.46-1.94)$ & 1.00 (Ref) & $1.55(1.34-1.78)$ \\
\hline Multivariable-adjusted HR $\mathrm{HR}^{\mathrm{a}}(95 \% \mathrm{Cl})$ & 1.00 (Ref) & $1.30(1.13-1.50)$ & 1.00 (Ref) & $1.40(1.21-1.63)$ & 1.00 (Ref) & $1.31(1.13-1.51)$ \\
\hline \multicolumn{7}{|l|}{ Non-cardiovascular mortality } \\
\hline Crude HR $(95 \% \mathrm{Cl})$ & 1.00 (Ref) & $1.27(1.17-1.38)$ & 1.00 (Ref) & $1.29(1.19-1.40)$ & 1.00 (Ref) & $1.27(1.17-1.37)$ \\
\hline Multivariable-adjusted HR $\mathrm{HR}^{\mathrm{a}}(95 \% \mathrm{Cl})$ & 1.00 (Ref) & $1.08(0.99-1.17)$ & 1.00 (Ref) & $1.05(0.96-1.14)$ & 1.00 (Ref) & $1.07(0.99-1.16)$ \\
\hline \multicolumn{7}{|l|}{ Myocardial infarction ${ }^{b}$} \\
\hline Crude HR $(95 \% \mathrm{CI})$ & 1.00 (Ref) & $1.56(1.27-1.92)$ & 1.00 (Ref) & $1.45(1.17-1.78)$ & 1.00 (Ref) & $1.54(1.25-1.89)$ \\
\hline Multivariable-adjusted HRa (95\% Cl) & 1.00 (Ref) & $1.61(1.30-1.99)$ & 1.00 (Ref) & $1.50(1.22-1.87)$ & 1.00 (Ref) & $1.59(1.28-1.96)$ \\
\hline \multicolumn{7}{|l|}{ Cerebral infarction ${ }^{\mathrm{b}}$} \\
\hline Crude HR $(95 \%$ CI) & 1.00 (Ref) & $1.52(1.34-1.71)$ & 1.00 (Ref) & $1.51(1.34-1.71)$ & 1.00 (Ref) & $1.54(1.36-1.74)$ \\
\hline Multivariable-adjusted HR $(95 \% \mathrm{Cl})$ & 1.00 (Ref) & $1.39(1.23-1.58)$ & 1.00 (Ref) & $1.40(1.24-1.60)$ & 1.00 (Ref) & $1.42(1.25-1.61)$ \\
\hline \multicolumn{7}{|l|}{ Cerebral hemorrhage $^{b}$} \\
\hline Crude HR $(95 \% \mathrm{CI})$ & 1.00 (Ref) & $0.95(0.76-1.18)$ & 1.00 (Ref) & $1.04(0.83-1.29)$ & 1.00 (Ref) & $0.98(0.79-1.22)$ \\
\hline Multivariable-adjusted HRa $(95 \% \mathrm{Cl})$ & 1.00 (Ref) & $0.87(0.69-1.08)$ & 1.00 (Ref) & $0.93(0.74-1.17)$ & 1.00 (Ref) & $0.89(0.71-1.12)$ \\
\hline
\end{tabular}


Table 4. Health Care Utilization and Costs by Level of Continuity of Care $(\mathrm{N}=47,433)$

\begin{tabular}{|c|c|c|c|c|c|c|}
\hline \multirow[b]{2}{*}{ Characteristic } & \multicolumn{2}{|c|}{$\begin{array}{l}\text { Most Frequent } \\
\text { Provider Continuity }\end{array}$} & \multicolumn{2}{|c|}{$\begin{array}{l}\text { Modified, Modified } \\
\text { Continuity Index }\end{array}$} & \multicolumn{2}{|c|}{$\begin{array}{l}\text { Continuity of Care } \\
\text { Index }\end{array}$} \\
\hline & $\begin{array}{l}\text { Above } \\
\text { Median }\end{array}$ & $\begin{array}{c}\text { Below } \\
\text { Median }\end{array}$ & $\begin{array}{c}\text { Above } \\
\text { Median }\end{array}$ & $\begin{array}{c}\text { Below } \\
\text { Median }\end{array}$ & $\begin{array}{l}\text { Above } \\
\text { Median }\end{array}$ & $\begin{array}{l}\text { Below } \\
\text { Median }\end{array}$ \\
\hline \multicolumn{7}{|l|}{ 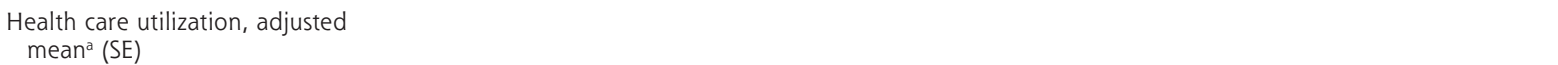 } \\
\hline Total inpatient days (2005-2010) & $7.4(0.4)$ & $11.4(0.4)$ & $7.4(0.4)$ & $11.4(0.4)$ & $7.4(0.4)$ & $11.4(0.4)$ \\
\hline Difference $(95 \% \mathrm{Cl})$ & \multicolumn{2}{|c|}{$4.0(2.8-5.2)$} & \multicolumn{2}{|c|}{$4.0(2.8-5.2)$} & \multicolumn{2}{|c|}{$4.0(2.9-5.2)$} \\
\hline Total outpatient days (2005-2010) & $22.5(0.2)$ & $25.4(0.2)$ & $22.1(0.2)$ & $25.8(0.2)$ & $22.5(0.2)$ & $25.4(0.2)$ \\
\hline Difference $(95 \% \mathrm{Cl})$ & \multicolumn{2}{|c|}{$2.9(2.3-3.4)$} & \multicolumn{2}{|c|}{$3.7(3.1-4.2)$} & \multicolumn{2}{|c|}{$2.9(2.3-3.5)$} \\
\hline \multicolumn{7}{|l|}{ Health care costs, 2005-2010, $\$$ (US) } \\
\hline Total inpatient cost, adjusted mean ${ }^{\mathrm{a}}$ (SE) & $853.7(31.7)$ & $1294.5(31.6)$ & $844.7(32.3)$ & $1297.1(31.7)$ & $851.5(31.7)$ & $1297.3(31.6)$ \\
\hline Difference $(95 \% \mathrm{Cl})$ & \multicolumn{2}{|c|}{$440.9(352.6-529.2)$} & \multicolumn{2}{|c|}{$452.4(362.3-542.5)$} & \multicolumn{2}{|c|}{$445.7(357.5-534.0)$} \\
\hline Total outpatient cost, adjusted mean ${ }^{\mathrm{a}}$ (SE) & $457.5(17.7)$ & $574.6(17.6)$ & $446.5(18.0)$ & $583.6(17.7)$ & $456.1(17.7)$ & $576.1(17.6)$ \\
\hline Difference $(95 \% \mathrm{Cl})$ & \multicolumn{2}{|c|}{$117.0(67.7-166.3)$} & \multicolumn{2}{|c|}{$136.7(86.5-187.0)$} & \multicolumn{2}{|c|}{$119.7(70.5-169.0)$} \\
\hline Total cost, adjusted mean ${ }^{\mathrm{a}}$ (SE) & $1311.1(38.0)$ & $1869.2(37.9)$ & $1291.3(38.6)$ & $1880.6(38.0)$ & $1307.7(37.9)$ & $1873.4(37.9)$ \\
\hline Difference $(95 \% \mathrm{Cl})$ & \multicolumn{2}{|c|}{$557.9(452.3-663.5)$} & \multicolumn{2}{|c|}{$589.1(481.4-696.9)$} & \multicolumn{2}{|c|}{$565.5(459.8-671.2)$} \\
\hline \multicolumn{7}{|c|}{$\mathrm{Cl}=$ confidence interval; $\mathrm{SE}=$ standard error. $\$ 1$ (US) = $\$ 1,100$ (Korean won), as of 2012.} \\
\hline \multicolumn{7}{|c|}{ Note: All $P$ values comparing above to below median utilization and cost parameters $<0.001$. } \\
\hline \multicolumn{7}{|c|}{$\begin{array}{l}\text { aMultivariable adjustments included age, sex, income level (quartile), Charlson comorbidity index, number of visits during the first } 2 \text { years, and residential area (for } \\
\text { detail, see text). }\end{array}$} \\
\hline
\end{tabular}

better self-management behaviors ${ }^{11,15}$ and to increase adherence to medication recommendations, probably because of greater trust ${ }^{46-48}$ and to have higher satisfaction with their physicians. ${ }^{47,49}$ Indeed, continuity of care has been associated with lower $\mathrm{HbA}_{1 \mathrm{C}}$ levels in patients with diabetes ${ }^{11,15}$ and with lower blood pressure in hypertensive patients, ${ }^{34}$ but our study provides for the first time a direct link between continuity of care, clinical end points, and all-cause and causespecific mortality.

The increased mortality associated with lower continuity of care of patients with cardiovascular risk factors in our study was largely due to increases in cardiovascular mortality. In addition to cardiovascular mechanisms, patients who have a sustained relationship with a physician may receive other preventive services ${ }^{11,14,17,22,48,50,51}$ and better quality of care for other comorbid conditions. ${ }^{52}$ It is thus possible that continuity of care for cardiovascular chronic conditions may also result in reduced non-cardiovascular mortality, but in our data these collateral effects were only marginal.

Consistent with previous studies, ${ }^{20}$ we also found reduced resource utilization and health care costs in subsequent years in groups with higher continuity of care. The association was stronger for inpatient care utilization and costs than for outpatient care costs ${ }_{1}{ }^{17}$ suggesting that the main benefit of continuity of care was to reduce emergency department visits ${ }^{19,21,22,28,35,53}$ and hospitalizations, ${ }^{17,27,28,35}$ the most costly elements of health care. In addition, the reduction in cardiovascular complications seen in our study should also contribute to reduced resource utilization and health care costs. A previous study has reported increased test repetition with higher continuity of care, ${ }^{26}$ but the implications of this finding were unclear, since this could be related to more careful disease monitoring.

\section{Study Limitations}

Several limitations need to be considered in the interpretation of our findings. First, we measured commonly used indices of continuity of care that assess informational and longitudinal continuity of care related to the pattern of visits. Interpersonal continuity, characterized by personal trust and responsibility in the relationship between patient and physician, represents a higher dimension in the hierarchical definition of continuity of care, ${ }^{41,54}$ but it was not assessed in this study because its assessment requires subjective measures. ${ }^{38}$ Informational and longitudinal continuity of care, however, are prerequisites for interpersonal continuity and provide a solid foundation for exploring higher dimensions of continuity of care. ${ }^{38,39}$

Second, we lacked details on process measures such as blood pressure, cholesterol, or $\mathrm{HbA}_{1 \mathrm{C}}$ levels as well as well as data on prescription treatments and compliance. Furthermore, the Charlson comorbidity index could not fully capture disease severity. Inclusion of such data in future studies is warranted to establish the mechanisms through which continuity of care leads to better outcomes.

Third, the observational nature of our study leaves room for unmeasured confounding and other potential 
sources of bias. For example, patients with mild conditions may show low compliance and continuity of care, or patients experiencing adverse health outcomes may change physicians. Also, continuity of care may be a marker of patient or health care system characteristics related to better health outcomes. ${ }^{10,12,15}$ Randomized clinical trials, however, are impractical for evaluating continuity of care. Finally, our results were derived in a health care system with universal coverage, high level of access to care, and free choice of physician, and may not be generalizable to other health care systems with different structures.

\section{Implications}

In spite of these limitations, our findings have significant policy implications given the way health care systems are increasingly fragmented and cost containment is increasingly important. Our study provides much needed empirical evidence that continuity of care is associated with reduced mortality, morbidity, and health care expenses and may thus provide added value in the management of chronic conditions. Health care systems should be designed to support long-term trusting relationships between patients and physicians, and health policies should encourage patients to concentrate their care with one physician..$^{55}$

To read or post commentaries in response to this article, see it online at http://www.annfammed.org/content/12/6/534.

Submitted October 30, 2013; submitted, revised, May 22, 2014; accepted June 25, 2014.

Key words: continuity of care; mortality; cardiovascular diseases; health care costs

Funding support: This work was supported by a grant from the South Korean Ministry of Health \& Welfare, No. 800-20110189.

Author affiliations: Department of Family Medicine \& Health Promotion Center, Seoul National University Hospital, Seoul, Republic of Korea (D.W.S., H.L., H.K., B.C.); Department of Family Medicine, College of Medicine, Seoul National University, Seoul, Republic of Korea (D.W.S., H.L., B.C.); JW Lee Center for Global Medicine, College of Medicine, Seoul National University, Republic of Korea (D.W.S.); Department of Health Sciences and Technology, Samsung Advanced Institute for Health Sciences and Technology, Sungkyunkwan University, Seoul, Republic of Korea (J.C.); Department of Epidemiology, Johns Hopkins Bloomberg School of Public Health, Baltimore, Maryland (J.C., E.G.); Department of Health, Behavior, and Society, Johns Hopkins Bloomberg School of Public Health, Baltimore, Maryland (J.C.); Cancer Policy Branch, National Cancer Control Institute, National Cancer Center, Goyang, Republic of Korea (H.K.Y.); Department of Social and Preventive Medicine, Samsung Biomedical Research Institute, Sungkyunkwan University School of Medicine, Suwon, Republic of Korea (J.H.P.); Department of Health Policy and Management, College of Medicine, Seoul National University, Seoul, Republic of Korea (J.O., H.K.Y.); Health Insurance Review \& Assessment Research Institute, Health Insurance Review and Assessment Service, Seoul, Republic of Korea (S.H.); Department of Medicine and
Welch Center for Prevention, Epidemiology, and Clincal Research, Johns Hopkins Medical Institutions, Baltimore, Maryland (E.G.); Area of Cardiovascular Epidemiology and Population Genetics, National Center for Cardiovascular Research (CNIC), Madrid, Spain (E.G.)

Prior presentation: This work was presented at the Spring meeting of the Korean Academy of Family Medicine, April 5, 2013, Daegu, Korea.

Supplementary materials: Available at http://www.AnnFamMed. org/content/12/6/534/suppl/DC1/

\section{References}

1. Committee on the future of primary care. Primary Care: America's Health in a New Era. 1st ed. Washington, DC: Institute of Medicine: National Academy of Sciences; 1996.

2. van Walraven C, Oake N, Jennings A, Forster AJ. The association between continuity of care and outcomes: a systematic and critical review. J Eval Clin Pract. 2010;16(5):947-956.

3. Gray DP, Evans P, Sweeney K, et al. Towards a theory of continuity of care. J R Soc Med. 2003;96(4):160-166.

4. Flocke SA, Stange KC, Zyzanski SJ. The impact of insurance type and forced discontinuity on the delivery of primary care. J Fam Pract. 1997;45(2):129-135.

5. Saultz JW, Albedaiwi W. Interpersonal continuity of care and patient satisfaction: a critical review. Ann Fam Med. 2004;2(5):445-451.

6. Okie S. The evolving primary care physician. N Engl J Med. 2012; 366(20):1849-1853.

7. Baker R. Will the future GP remain a personal doctor? $\mathrm{Br} J \mathrm{Gen}$ Pract. 1997;47(425):831-833.

8. Freeman GK. The concept of continuity of care in European General Practice. Eur J Gen Pract. 2000;6(4):118-119.

9. Guthrie $B$, Wyke $S$. Does continuity in general practice really matter? BMJ. 2000;321(7263):734-736.

10. Saultz JW, Lochner J. Interpersonal continuity of care and care outcomes: a critical review. Ann Fam Med. 2005;3(2):159-166.

11. O'Connor PJ, Desai J, Rush WA, Cherney LM, Solberg LI, Bishop DB. Is having a regular provider of diabetes care related to intensity of care and glycemic control? J Fam Pract. 1998;47(4):290-297.

12. Parchman ML, Burge SK; Residency Research Network of South Texas Investigators. Continuity and quality of care in type 2 diabetes: a Residency Research Network of South Texas study. J Fam Pract. 2002;51(7):619-624.

13. Safran DG, Taira DA, Rogers WH, Kosinski M, Ware JE, Tarlov AR. Linking primary care performance to outcomes of care. J Fam Pract. 1998;47(3):213-220.

14. Ettner SL. The relationship between continuity of care and the health behaviors of patients: does having a usual physician make a difference? Med Care. 1999;37(6):547-555.

15. Parchman ML, Pugh JA, Noël PH, Larme AC. Continuity of care, self-management behaviors, and glucose control in patients with type 2 diabetes. Med Care. 2002;40(2):137-144.

16. Mainous AG III, Koopman RJ, Gill JM, Baker R, Pearson WS. Relationship between continuity of care and diabetes control: evidence from the Third National Health and Nutrition Examination Survey. Am J Public Health. 2004;94(1):66-70.

17. Weiss LJ, Blustein J. Faithful patients: the effect of long-term physician-patient relationships on the costs and use of health care by older Americans. Am J Public Health. 1996;86(12):1742-1747.

18. De Maeseneer JM, De Prins L, Gosset C, Heyerick J. Provider continuity in family medicine: does it make a difference for total health care costs? Ann Fam Med. 2003;1(3):144-148. 
19. Dreiher J, Comaneshter DS, Rosenbluth Y, Battat E, Bitterman $H$, Cohen AD. The association between continuity of care in the community and health outcomes: a population-based study. Isr J Health Policy Res. 2012;1(1):21.

20. Cornelius LJ. The degree of usual provider continuity for African and Latino Americans. J Health Care Poor Underserved. 1997;8(2):170-185.

21. Ionescu-Ittu R, McCusker J, Ciampi A, et al. Continuity of primary care and emergency department utilization among elderly people. CMAJ. 2007;177(11):1362-1368.

22. Menec VH, Sirski M, Attawar D. Does continuity of care matter in a universally insured population? Health Serv Res. 2005;40(2):389-400.

23. Gill JM, Mainous AG III, Diamond JJ, Lenhard MJ. Impact of provider continuity on quality of care for persons with diabetes mellitus. Ann Fam Med. 2003;1(3):162-170.

24. Hänninen J, Takala J, Keinänen-Kiukaanniemi S. Good continuity of care may improve quality of life in Type 2 diabetes. Diabetes Res Clin Pract. 2001;51(1):21-27.

25. Broom DH. Familiarity breeds neglect? Unanticipated benefits of discontinuous primary care. Fam Pract. 2003;20(5):503-507.

26. van Walraven C, Cernat G, Austin PC. Effect of provider continuity on test repetition. Clin Chem. 2006;52(12):2219-2228.

27. Gill JM, Mainous AG III. The role of provider continuity in preventing hospitalizations. Arch Fam Med. 1998;7(4):352-357.

28. Wasson JH, Sauvigne AE, Mogielnicki RP, et al. Continuity of outpatient medical care in elderly men. A randomized trial. JAMA. 1984; 252(17):2413-2417.

29. Wolinsky FD, Bentler SE, Liu L, et al. Continuity of care with a primary care physician and mortality in older adults. J Gerontol A Biol Sci Med Sci. 2010;65(4):421-428

30. Levene LS, Bankart J, Khunti K, Baker R. Association of primary care characteristics with variations in mortality rates in England: an observational study. PLoS One. 2012;7(10):e47800.

31. Honeyford K, Baker R, Bankart MJ, Jones D. Modelling factors in primary care quality improvement: a cross-sectional study of premature CHD mortality. BMJ 2013 Oct 23:3(10):e003391.

32. Pearson TA, Blair SN, Daniels SR, et al.; American Heart Association Science Advisory and Coordinating Committee. AHA Guidelines for Primary Prevention of Cardiovascular Disease and Stroke: 2002 Update: Consensus Panel Guide to Comprehensive Risk Reduction for Adult Patients Without Coronary or Other Atherosclerotic Vascular Diseases. Circulation. 2002;106(3):388-391.

33. Perk J, De Backer G, Gohlke H, et al.; European Association for Cardiovascular Prevention \& Rehabilitation (EACPR); ESC Committee for Practice Guidelines (CPG). European Guidelines on cardiovascular disease prevention in clinical practice (version 2012). The Fifth Joint Task Force of the European Society of Cardiology and Other Societies on Cardiovascular Disease Prevention in Clinical Practice (constituted by representatives of nine societies and by invited experts). Eur Heart J. 2012;33(13):1635-1701.

34. Phillips DM, Shear CL. Provider continuity and control of hypertension. J Fam Pract 1984;19(6):793, 797.

35. Chen CC, Chen SH. Better continuity of care reduces costs for diabetic patients. Am J Manag Care. 2011;17(6):420-427.
36. Cabana MD, Jee SH. Does continuity of care improve patient outcomes? J Fam Pract. 2004;53(12):974-980.

37. Pandhi N, Saultz JW. Patients' perceptions of interpersonal continuity of care. J Am Board Fam Med. 2006;19(4):390-397.

38. Adler R, Vasiliadis A, Bickell N. The relationship between continuity and patient satisfaction: a systematic review. Fam Pract. 2010;27(2): 171-178.

39. Christakis DA, Mell L, Koepsell TD, Zimmerman FJ, Connell FA. Association of lower continuity of care with greater risk of emergency department use and hospitalization in children. Pediatrics. 2001;107(3):524-529.

40. Cho B, Lee CM. Current situation of national health screening systems in Korea. J Korean Med Assoc. 2011;54:666-669.

41. Saultz JW. Defining and measuring interpersonal continuity of care. Ann Fam Med. 2003;1(3):134-143.

42. Given CW, Branson M, Zemach R. Evaluation and application of continuity measures in primary care settings. J Community Health. 1985;10(1):22-41

43. Magill MK, Senf J. A new method for measuring continuity of care in family practice residencies. J Fam Pract. 1987;24(2):165-168.

44. Bice TW, Boxerman SB. A quantitative measure of continuity of care. Med Care. 1977;15(4):347-349.

45. Koopman RJ, Mainous AG III, Baker R, Gill JM, Gilbert GE. Continuity of care and recognition of diabetes, hypertension, and hypercholesterolemia. Arch Intern Med. 2003;163(11):1357-1361.

46. Mainous AG III, Baker R, Love MM, Gray DP, Gill JM. Continuity of care and trust in one's physician: evidence from primary care in the United States and the United Kingdom. Fam Med. 2001;33(1):22-27.

47. Baker R, Mainous AG III, Gray DP, Love MM. Exploration of the relationship between continuity, trust in regular doctors and patient satisfaction with consultations with family doctors. Scand J Prim Health Care. 2003;21(1):27-32.

48. Parchman ML, Burge SK. The patient-physician relationship, primary care attributes, and preventive services. Fam Med. 2004;36(1):22-27.

49. Hjortdahl P, Laerum E. Continuity of care in general practice: effect on patient satisfaction. BMJ. 1992;304(6837):1287-1290.

50. Flocke SA, Stange KC, Zyzanski SJ. The association of attributes of primary care with the delivery of clinical preventive services. Med Care. 1998;36(8)(Suppl):AS21-AS30.

51. O'Malley AS, Mandelblatt J, Gold K, Cagney KA, Kerner J. Continuity of care and the use of breast and cervical cancer screening services in a multiethnic community. Arch Intern Med. 1997;157(13):1462-1470.

52. Cree M, Bell NR, Johnson D, Carriere KC. Increased continuity of care associated with decreased hospital care and emergency department visits for patients with asthma. Dis Manag. 2006;9(1):63-71.

53. Gill JM, Mainous AG III, Nsereko M. The effect of continuity of care on emergency department use. Arch Fam Med. 2000;9(4):333-338.

54. Jee $\mathrm{SH}$, Cabana MD. Indices for continuity of care: a systematic review of the literature. Med Care Res Rev. 2006;63(2):158-188.

55. Miller TE. Managed care regulation: in the laboratory of the states. JAMA. 1997;278(13):1102-1109. 